\title{
RESEARCH PAPER ON WASTEWATER TREATMENT PLANT USING PLC \& SCADA
}

\author{
Ankit R. Rajhans, Sumit S. More, Saurabh V. Gambhir, Vaibhav H. Deshmukh \\ Department of Electrical Engineering \\ Vishwaniketan Institute of Management and Engineering Technology. \\ Mumbai- 410202, India \\ Prof. Sarthak k.Joshi \\ (Assistant Professor) \\ Department of Electrical Engineering \\ Vishwaniketan Institute of Management and Engineering Technology. \\ Mumbai- 410202, India
}

\begin{abstract}
The Effective solution for waste water treatment plant consists of number of small components based on control system including sensors, actuators, motors, etc. PLC (Programmable Logic Controller) continuously monitor the operation of different devices connected to it such as pumps, motors, sensors and other devices. The main aim of using PLC is that there is an increase in the efficiency as well as the accuracy of the process. Here The signals from the field is collected by the sensors which acts as an input to the PLC \& feeds actual information of the components present on the field. Programmable logic controllers (PLC) are used to control various processes based on the data and built-in algorithm. Based on the design and other specification associated with Programmable logic controller, a control panel is designed in suitable SCADA software for the control and monitoring of waste water treatment plant. This provides flexibility for the control of different processes directly from the SCADA software along with the manual control from PLC controller.
\end{abstract}

A program that provides the appropriate behaviour of the valve, placed at the entrance and the control of the pumps was written in a ladder diagram. The alarm and monitoring system are of the highest importance.

The real time simulation of the entire operation is displayed on the SCADA screen. This feature of the waste water treatment plant is of utmost importance to analyze even minute details of the system.

Keywords- Programmable logic controller (PLC), Automation, Waste-water, Supervisory Control and Data Acquisition System (SCADA).

\section{INTRODUCTION}

Waste water is generated from many industrial as well as domestic applications. Typical residential water usage is from 150 to 200 liters per person per day. SeventyTwo percent of the population is linked to a centralized wastewater plant and treatment system, while the remaining 27 percent uses on-site septic systems. The water flows after washing becomes wastewater better known as sewage that must be cleaned up before it is returned to the environment for reuse. In some way or the other ways, sufficient amount of water is recycled. Earlier In the past, People would think that there is no way of reusing the water after it is used since there was no advancement in the technology and no effective ways of waste water treatment available. However, nowadays different waste water processes are available and that too employing different technologies. Purifiers implementing plasma technology, reverse osmosis technology, uv ray light technology, etc. are available in the market.

Here, we introduce simple and quite effective waste water purifier with four stages such as filtration, coagulation, chlorination and $\mathrm{pH}$ adjustment stage. This whole consists of different sensors and other automatic operative devices make purifier work automatic and efficient. Moreover, SCADA technology employed here helps to get the real time simulation of the process with effective control of the plant from the control room. Leakage sensors, solenoid valves, peristaltic pump are also connected and properly interfaced to the PLC, so that reliability would not be compromised.

Along with micro-organisms such as bacteria and other viruses, waste water has to be treated effectively so that, there should not be a presence of black color along with taste issues must also be taken care of. More Importantly, Waste water if discharged directly into rivers, lakes and oceans it would to a large extent affect the aquatic creatures and increases the water pollution which is not desirable. On the other hand, Waste water if used for agricultural purposes without being treated properly then on a large basis it affects the chemical properties of land making it infertile. Owing to these certain problems associated with waste water there is a need of employing efficient devices for sensing, controlling and filtering of the waste water.

- Comprehensive literature review on nature and solutions of waste water treatment plant was conducted by AWWA research foundation in 1969.

- In the research, Major emphasis was on to determine the quality and quantities of waste produced. Along with that characteristics of waste 
produced was also taken care of with existing methods of waste disposal.

\section{Presence of waste water treatment plants in India:}

- The amount of waste produced in India is comparatively greater than the capacity of the waste water treatment plant installed. However, there are some regions where efficient treatment of waste is carried out which is almost around $95-98 \%$ of the waste generated.

- In India, Capital city Delhi has the largest capacity of treatment plant installed but meets only $60 \%$ of the waste generated in the city while remaining waste is still not treated properly \& recycled.

- On the other hand, Mumbai has the second largest waste water treatment plant in terms of capacity but meets only $80 \%$ of the total waste generated through the city.

- There are only five major metro cities where efficient treatment of waste water is carried out and that too around $100 \%$ of the total waste generated in the cities.

- Almost all other metropolitan cities have capacity of treatment plant below $50 \%$ of the total waste generated in the city.

\section{Efforts to expand municipal sewage treatment:}

- Cities cannot tackle the sewage problem alone and considering this thing, The Central Government launched the Ganga Action Plan.

- Action plans for other rivers were also formulated to clean the waste water so as to improve the quality of river water. Separate programs were initiated under the National River Conservation plan (NRCP).

\section{SOFTWARE REQUIREMENT}

- $\quad$ PLC Software- RS LOGIX 500

- Communication Software- RS LINX CLASSIC

- $\quad$ SCADA Software- FACTORY TALKVIEW

- $\quad$ PLC Used- Allen Bradly 1400 (Series A)

\section{HARDWARE REQUIREMENT}

- Bar-screeners, PLC, SCADA software

- $\quad \mathrm{pH}$ sensor, PUMP motors, Solenoid valves

- Tanks, Limit Sensor and other auxiliary components required.

\section{BLOCK DIAGRAM}

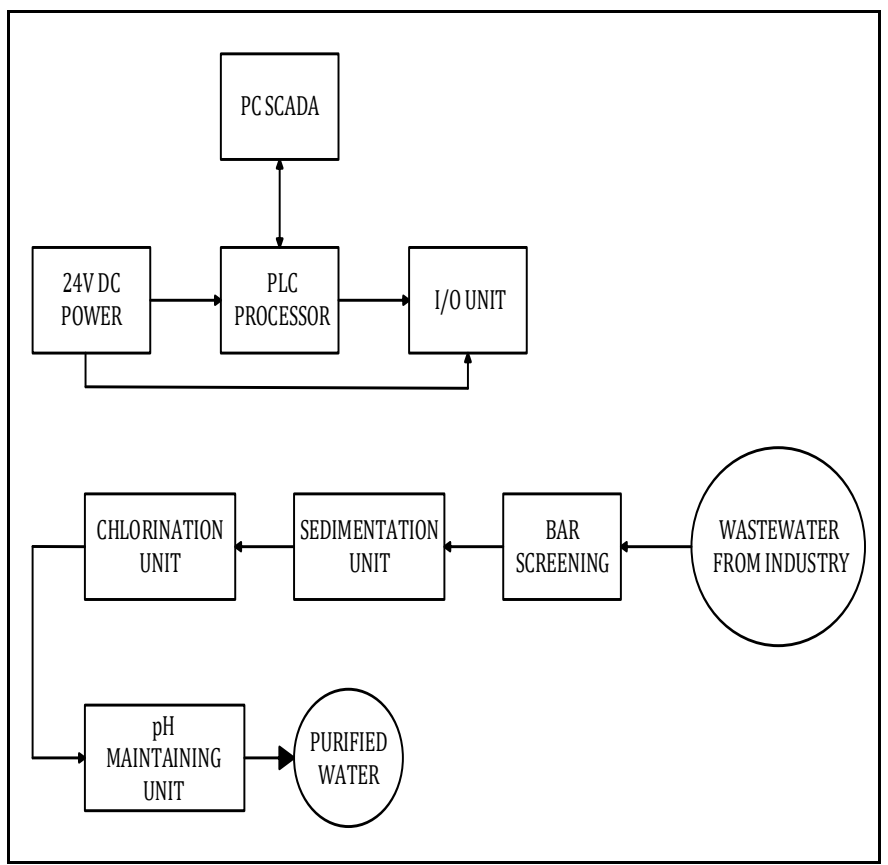

Figure 1: Block Diagram

\section{DIFFERENT PROCESSES}

1) Bar Screening-

This process is quite crucial for the filtration or separation of the solid impurities such as plastic, wood, cloths and other physical impurities present in the waste water. In this process waste water is automatically sent inside from the inlet tank and the screening/separation process is carried out which is required for the effective treatment of the water in the further stages.

\section{2) Coagulation-}

The Filtered water from the previous stage is passed on to this stage where the solid impurities which are not removed by bar screening are settled at the bottom of the tank by adding required amount of aluminium sulphate (Alum). Here, required drops of alum are poured into the water by Peristaltic pump which receives signal from the PLC depending on the previous process. The amount of alum which is to be added is dependent on a particular application.

\section{3) Chlorination-}

The Coagulated Water from tank 2 is automatically sent to chlorination tank as soon as coagulation process is completed. In chlorination unit, sufficient amount of chlorine is mixed with the coagulated water to kill microorganisms such as bacteria, germs, etc. Moreover, it is an effective way to purify the color of the waste water. Here, after adding chlorine into the water some time is provided for uniformly mixing the chlorine by stirring. After sufficient stirring time which is set up as per the application, 
processed water is delivered to the $\mathrm{pH}$ adjustment tank by opening the solenoid valve

\section{4) pH Maintaining Unit-}

Here processed water from the previous stage is taken and continuously monitored until the $\mathrm{pH}$ value of the water is 6 or 7 . Liquid having $\mathrm{pH}$ less than 7 is acidic in nature and above 7 acts like a base. In this stage care is taken to deliver filtered water with $\mathrm{pH}$ value close to the desired value or value demanded by a particular application.

\section{PROCESS FLOW DIAGRAM}

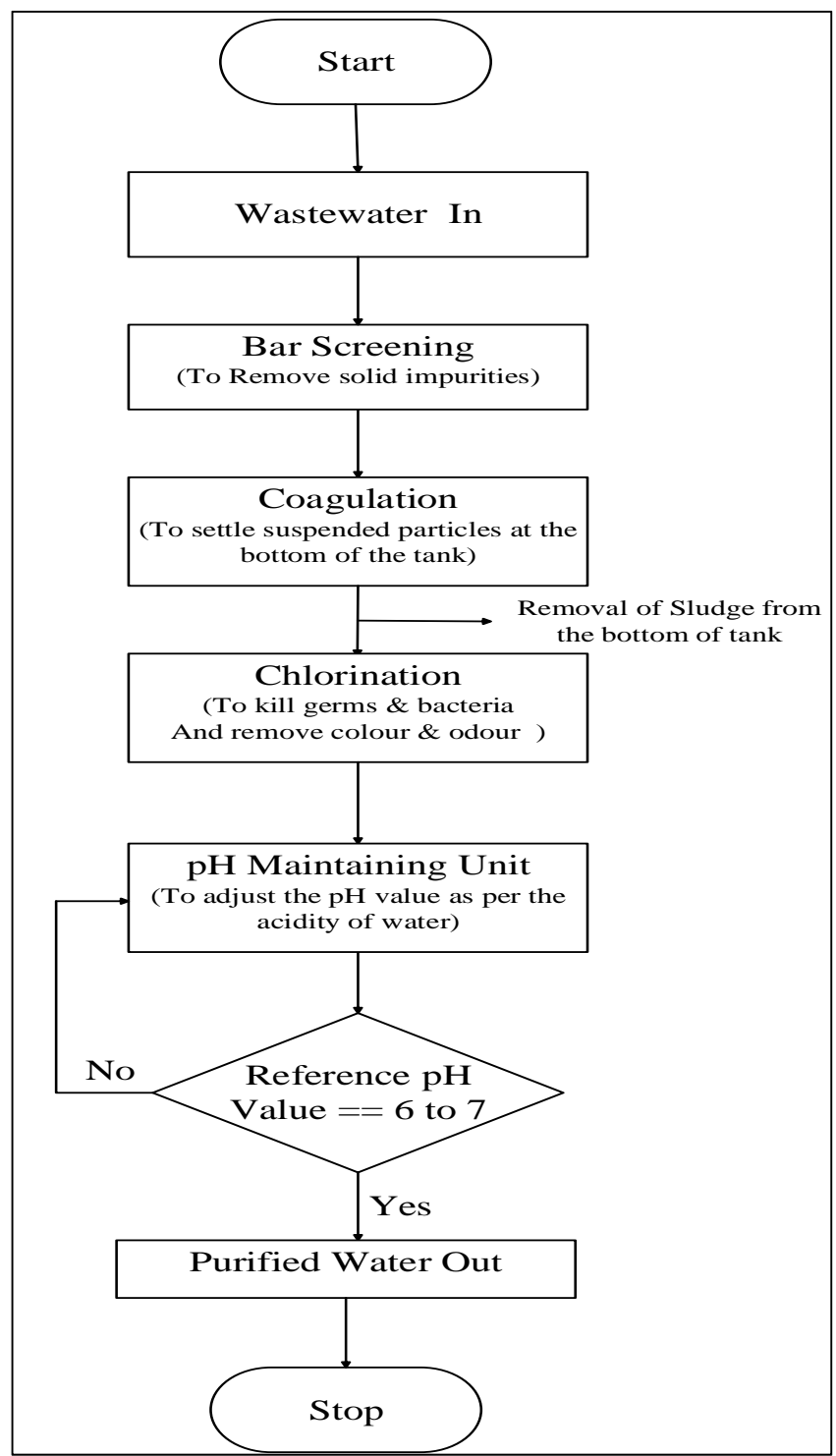

Figure 2: Process Flow Diagram

For the effective understanding of what actually happening in the waste-water treatment plant, it is necessary to understand the flow of the whole process \& this is efficiently determined by Process Flow Diagram.

To efficiently treat the waste water, it is necessary that individual process should be accurately controlled and processed so as to improve the overall efficiency of the waste water treatment plant.

This wastewater treatment plant consists of four main stages i.e. screening, sedimentation, chlorination and oxidation to filter out the waste water and transform that into a useful one.

The process flow of the waste water treatment plant is given as follows-

First of all, Solid impurities which are present in the waste water in the form of plastic, paper, pebbles, etc. are removed. For that Bar-screeners are employed.

After that, Dissolved impurities present in the waste water are brought out at the bottom of the tank from where they are scrapped out. Then as per the application, the $\mathrm{pH}$ of the water is set by adding alum and chlorine in the water which is fulfilled with the help of $\mathrm{pH}$ sensor. Chlorination process is further followed by oxidation process which is necessary to remove Sulphur, manganese and most importantly, it removes odor and taste problems associated with purified water.

\section{I/O COUNTS}

The term I/O represents Input \& Output. I/O are used to collect data from the field by sensors and feed that respective data to the output devices connected to the output port of controller. Internally, Programmable logic controller consists of $\mathrm{I} / \mathrm{O}$ cards to which these $\mathrm{I} / \mathrm{O}$ devices are connected. By employing these I/O devices, Changes in the Input quantity can be sensed and accordingly controlled which is desired for efficient controlling.

There are mainly two types of I/O devices depending on the way they function.

- Digital I/O Devices

- Analog I/O Devices

○

Digital I/O Devices-

Digital I/O Devices are basically in binary form i.e. either 0 or 1 . They may be closed or opened, $\mathrm{ON}$ or SOFF, etc. Example of Digital input devices include different switches which include push buttons, latches, limits switches and other devices which have only 2 stable states either low or high.

On the other hand, Devices such as motors, solenoid valves, pumps, etc. are the examples of digital output devices.

\section{○ Analog I/O Devices-}

Analog I/O Devices are able to respond even to intermittent values between high and low. They basically respond to continuous change or accept time varying signals 
from the surroundings. Analog inputs are temperature, pressure, speed, force, etc.

On the other hand, Analog output signals are valve position, speed of the motor, pressure, output temperature, etc. Analog $\mathrm{I} / \mathrm{O}$ devices help the PLC to communicate with the outer environment so as to respond to the physical changes. Analog input which is a sensor accepts the physical or analog value and converts the same into electrical sensors which is then utilized for different subprocesses.

I/O Modules communicate with PLC in the following ways-

- Device internal network

- Rack

- Backplane Extension

The Number of I/O devices used by this proposed waste water treatment plant is as given below-

\section{TOTAL I/O COUNT-23}

\begin{tabular}{|l|l|}
\hline Input Count & Output Count \\
\hline Push Buttons - 2 & Valves - 6 \\
\hline pH sensor - 1 & Stirrer Motors - 3 \\
\hline Limit Switches -8 & Peristaltic Pump -3 \\
& \\
\hline
\end{tabular}

Figure 3: I/O Count Table

- Push buttons, Limit switches - Discrete Input devices

- $\quad \mathrm{pH}$ sensor- Analog input devices

- Solenoid valves, Stirrer motors, pumps- Discrete output devices

\section{PIPING AND INSTRUMENTATION DIAGRAM}

A Piping and Instrumentation Diagram is a detailed schematic which exhibits different instrumentation and control devices of the process with piping and process equipment.

Piping and instrumentation diagram is also known as Process and Instrumentation diagram which indicates the more detailed flow of different plant processes along with the relationship among the major plant equipment of a plant. P\&ID is also defined as the interconnection of various process equipment and the instrum-entation employed for controlling different processes. The P\&ID Diagram is composed of various mechanical equipment such as cooling towers, motor pumps, columns, Fluid tanks, pig traps, etc.

The process control designation and instrumentation including Types of valves and their identifications, control of input and output element such as vents, drains, special fittings, etc.

Process and instrumentation diagram also play an important role while carrying out maintenance and modification of the processes after initial planning. P\&ID is originally designed from process flow data sheet, instrumentation engineering design and mechanical input design. Process and instrumentation diagram also help to provide a visual indication of simulation design of Scada screen. So that, before designing a Scada screen, the position of all the equipment involved in the process are determined with the help of P\&ID.

Furthermore, P\&ID helps designer to estimate number of components involved in the process along with their position which is of utmost importance while designing a SCADA screen.

Below shown a P\&ID Diagram consisting of four different processes wherein tanks are interconnected by pipes.

Four tanks shown are Bar-Screening tank, Coagulation tank, Chlorination tank and pH adjustment tank. Limit Switches along with peristaltic pumps and valves are also shown in the P\&ID Diagram.

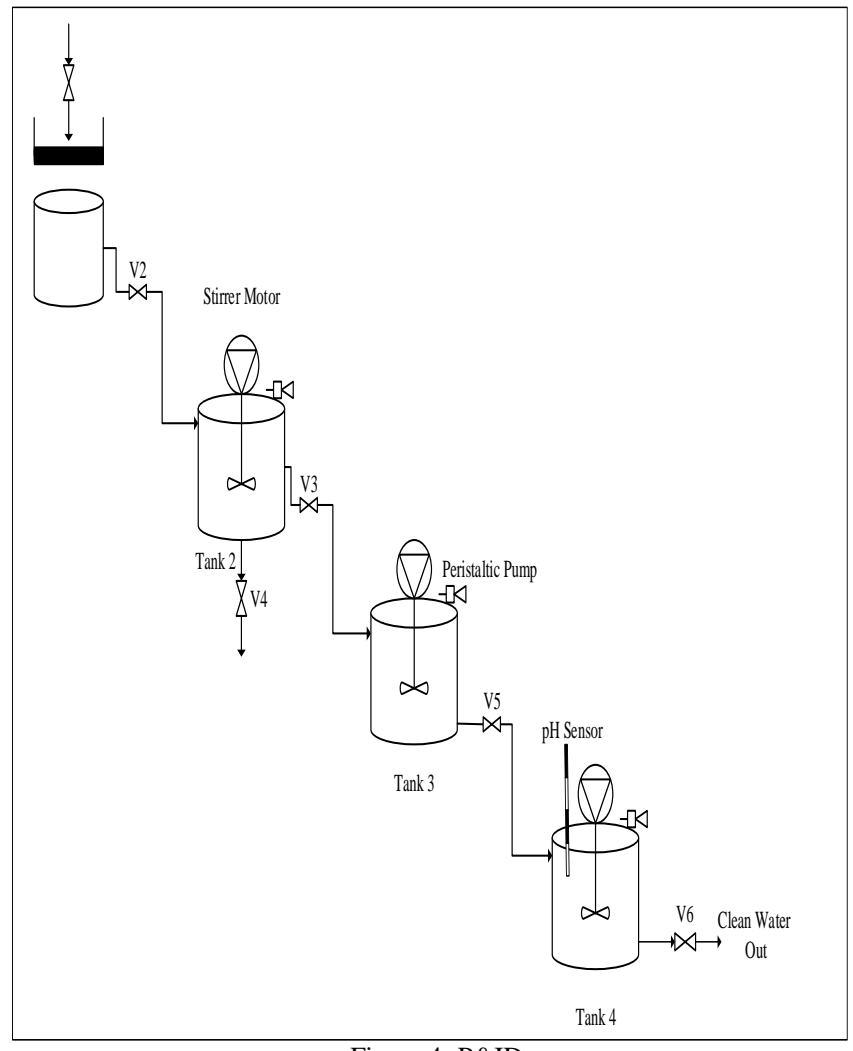

Figure 4: P\&ID 


\section{RESULT}

\section{Control Window-}

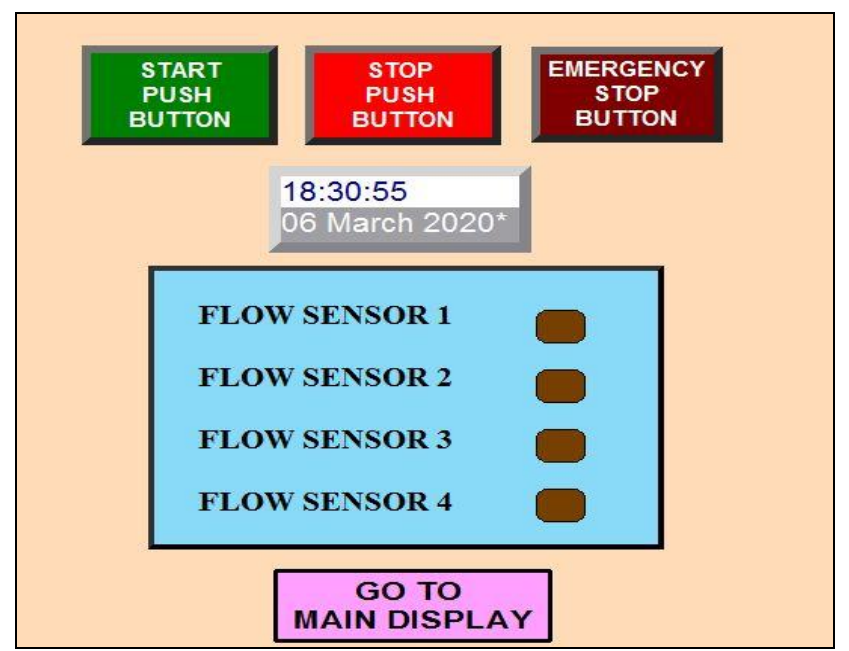

The above SCADA window consists of a control panel wherein different controls are shown. The Top 3 main controls are START, STOP AND EMERGENCY STOP. These controls are provided on the software so that operation can be activated or deactivated from the control room also.

Below These 3 controls, Individual indication of processes such as Bar-Screening tank, Coagulation tank, Chlorination tank and $\mathrm{pH}$ adjustment tank are shown. Top 2 controls provide indication or status of the individual tank whether it is empty or full and bottom indication is for the status of the pressure sensor. Bottom indication glows green normally and when pressure change is detected protection system gets activated with simultaneous indication on the control panel.

\section{Simulation Window-}

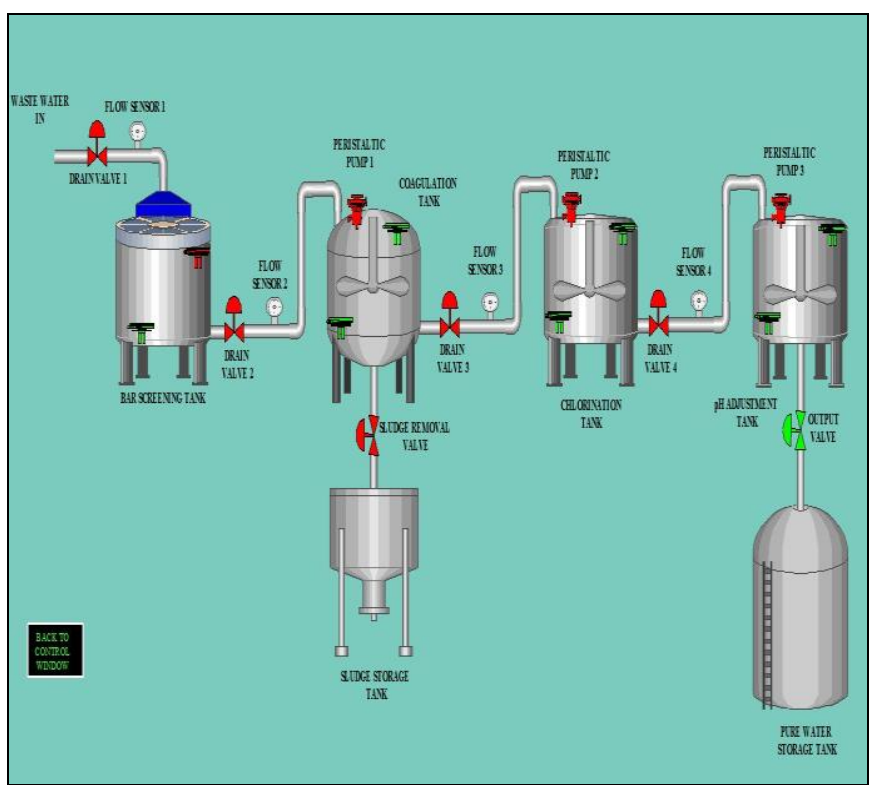

Above Simulation window exhibits a real time visualization of the waste water treatment plant which is generally observed from the control room. Depending on the abnormalities present in the system, indications are given by the respective devices and according to that control action is taken.

Here different valves are shown which is responsible to control the flow of water from one tank to another tank. Depending on the activation of limit switches, next valve of a particular process is opened and at the same time there is a closure of the previous valve. The real time visualization of entire process is displayed on the simulation window of the SCADA screen.

To shut down the process during leakage or under some abnormal condition so as to increase the reliability of the system, Pressure sensors are connected between the two respective processes so that under leakage condition, Waste water treatment plant will get shutdown and most importantly instead of shutting down the entire plant, only previous valve will get opened. So, no need to again carrying out the same process after rectification of the leakage problem.

At the coagulation tank, Sludge tank is provided to remove out the sludge which gets deposited at the bottom of the tank during coagulation process. Sludge removal valve automatically gets opened in every cycle of filtration and once sludge tank gets full, it is discharged out.

The filtered water finally is stored in the output water storage tank by automatically opening the outlet valve with the help of programmable logic controller (PLC). However, opening of the outlet valve is wholly dependent on the $\mathrm{pH}$ adjustment process. If the $\mathrm{pH}$ of the water is not between 6-7, The process of adjusting $\mathrm{pH}$ still continuous with simultaneous addition of baking soda which has the property of controlling the $\mathrm{pH}$ of the water.

\section{ADVANTAGES}

1. Increases energy as well as capital savings by employing real-time simulations and fully automatic operation by using PLC and SCADA.

2. Achieves improvement in the productivity, decreased in the operating costs, and better utilization of staff with advanced process automation, communication, and information management.

3. Reduce potential environmental problems such as overflow, with early detection of failures and weather warnings.

4. Track and control manpower costs through a centralized monitoring and control system that reduces the amount of time and energy that personnel must spend on auxiliary equipment operation and maintenance. 


\section{DISADVANTAGES}

1) Plant does not start automatically when power failure takes place or under abnormal conditions when there is a leakage in the tank or pipes or pumps used

2) Skilled labour workforce is required to operate the newly designed automated system.

\section{APPLICATIONS}

Water in the form of waste coming out of the industries, Residential Houses, Shopping malls, Colleges, etc. can be purified and be used for many domestic, Agricultural, commercial as well as can be reused again in the industries for different processes.

Applications possible are:

- $\mathrm{pH}$ control and alkalinity adjustment.

- Odour and corrosion control.

- Phosphorous removal work.

- Heavy metal precipitation.

- Industry water maintenance.

- Flocculation and solid particles separation.

\section{CONCLUSION}

Due to the continuous evolution in the automation technology especially in the field of PLC and SCADA, the waste-water treatment plant can be fully automates by employing different sensors and timers to improve the reliability of the treatment plant. PLC facilitates flexibility as well as ease of programming with high speed and better precision of operation, and also, due to its simple and easy to understand programming language, it is being used in several industrial applications world-wide. Moreover, it's wireless technology and inbuilt memory also makes the overall water treatment operation well-effective and efficient. Also, the proper interfacing between PLC and SCADA enables the remote.

\section{FUTURE SCOPE}

With UN reports, Warning of water crisis being faced by the two thirds of global population by 2025 . The Scope of waste water in future is large one as demand of water will be increasing in the future so in order to cater to this increasing water demand, waste water treatment plant in going to be highly valuable.

Waste water treatment plant in future can be employed in the following ways:

- Waste-water treatment plants

- Agricultural wastewater sewage plant

- Thermal power plants

- Leachate treatment plants
These Sewage water treatment plants can be installed in number of set ups which could be industrial, Institutional, In Residential colonies as well as in agricultural activities where large amount of water is required to grow crops.

Along with that in thermal powerplants and nuclear powerplants where high amount of steam is generated, at the inlet of Boiler waste water treatment plants can be installed so as to filter out all the solid as well as the dissolved impurities present in the inlet water. These increases the efficiency of steam generated which in- turns increase the overall efficiency of the plant.

\section{REFERENCES}

1) Bode R, Lee SH (2008) A research of studies on micellar enhanced ultrafiltration and Activated Carbon Fibre Processes. Environmental Engineering Research 13 (2) : 98 - 104.

2) Chakinala AG, Gogate PR., Burges AE, Bremner DH (2009) Industrial wastewater treatment.

3) J. Bouza-Fernandez, G. Gonzalez-Filgueira, S. de las Heras Jimenez, D.Vazquez-Gonzalez, "Expert System of a Sewage Treatment Plant for Wood Industry" (IEEE, 2010).

4) Bekiari V, Lianos P (2010) poly ( sodium acrylate ) hydrogels as potential $\mathrm{pH}$ - sensitive sorbents for the removal of model organic and inorganic pollutants fro water. Glob Nest J 12 (3) : $262-229$.

5) https://www.ijareeie.com/upload/2016/november/1 7_4_AUTOMATION.pdf, Anderson Elshaw; N. M. R. Hassan; M. M. K. Khan "CFD Modelling and Optimisation of a Waste Water Treatment Plant Bioreactor" -A Case Study 2016 3rd Asia-Pacific World Congress on Computer Science and Engineering (APWC on CSE).

6) https://www.engpaper.com/scada 2017.html.

7) https://www.researchgate.net/publication/31805670 3_PLC_and_SCADA_Based_Sewage_Water_Treat ment_Plant

8) https://ijedr.org/papers/IJEDR1901046.pdf.

9) http://irejournals.com/formatedpaper/1700683.pdf.

10) http://ciitresearch.org/dl/index.php/pdcs/article/vie w/PDCS052016007.

11) http://www.researchgate.net/publication/332183222 _Wastewater_Treatment_Methodologies_Review_ Article.

12) https://www.researchgate.net/profile/Dr_Arvind_C havhan/publication/230595234_Review_on_Waste _Water_Treatment_Technologies/links/0fcfd50353 b525083a000000/Review-on-Waste-Water-

Treatment

Technologies.pdf?origin=publication_detail.

13) http://www.wateronline.com

14) Sadhguru. (2018, march 22). world economic forum. Retrieved from www.weforum.org: 
https://www.weforum.org/agenda/2018/03/the-

clean-sweep-cleaning-up-india-s-rivers/

15) Tandon, K., \& Sinha, A. (2007). Evaluation Of Operation And Maintenance Of Sewage Treatment Plants In India-2007. CONTROL OF URBAN POLLUTION, 1-68.

16) Jamil, I., Jamil, R., Jamil, R., Jinquan, Z., \& Samee, A. (2013). Technical Communication of Automation Control System in Water Treatment Plant. International Journal of Innovation and Applied Studies ISSN 2028-9324 Vol. 4, 28-36.

17) Venkateswarlu, G., Sahu, J., Sriya, Y., \& Pappala, S. (2015, April). PLC and SCADA Based Secured and Sustainable Living. International Journal of Advanced Research in Electrical,Electronics and Instrumentation Engineering, 4, 1981- 1989. 